\title{
Resettlement after short prison sentences: what might work in England and Wales
}

Accepted version of article to appear in Probation Journal. Date of acceptance 22/4/20.

\section{Peter Raynor}

School of Law, Swansea University, UK.

p.raynor@swansea.ac.uk

\begin{abstract}
:
One of the advertised aims of the 'Transforming Rehabilitation' (TR) reforms in England and Wales was to extend compulsory post-custody supervision to prisoners serving short sentences who were outside the scope of existing resettlement provision. It is now well established that the arrangements introduced by TR for this group of prisoners have not been successful, having delivered high and often unmanageable caseloads, little help to service users and a greatly increased chance of recall to prison. The need which the reforms purported to meet remains unmet. There is little point in poorly designed and delivered provision; on the other hand, resources for the foreseeable future are not likely to support large increases in expenditure when so many parts of the criminal justice system require investment. This paper draws on research from the 1990s onwards on provision for this group of prisoners, and in particular the 'Pathfinder' projects of 1999-2003, as examples of what can be achieved on a voluntary basis. It is suggested that future provision for this group in England and Wales should be based on a more selective and individualised provision, with less coercion and more choice for service users.
\end{abstract}

\section{KEY WORDS:}

Resettlement; prisoners; voluntary after-care; Pathfinder research projects; Transforming Rehabilitation. 


\section{Resettlement after short prison sentences: what might work in England and Wales}

\section{Introduction: what went wrong with $\mathrm{TR}$, and what happened long before.}

When the Conservative-led coalition Government introduced its 'Transforming Rehabilitation' (TR) changes to probation services in 2015, most discussion of the new measures concentrated on the forced privatisation of the majority of probation work. Comment since then has continued to focus largely on this, including strong condemnation of the 'irredeemably flawed' model by the former Chief Inspector of Probation (HM Inspectorate of Probation 2019a: 3), and in 2019 the Government announced that all 'offender management' work would be returned to the public sector, although Community Punishment and 'interventions' would controversially remain with private sector providers. This article is concerned with a less discussed but very important aspect of TR, namely the provision made for resettlement and post-sentence supervision of people released from prison sentences of less than 12 months. The introduction of twelve months of statutory supervision for this large group of prisoners was intended to close a gap which had left without postrelease supervision a group of prisoners who had many problems and a high reconviction rate. It was expected to add about 40,000 new cases annually to the caseload, to be supervised mainly by the private-sector Community Rehabilitation Companies (CRCs). Superficially this looked like an improvement in services for a neglected group in undeniable need, who were serving prison sentences usually too short to offer any rehabilitative content but often long enough to lose accommodation or jobs. However, as happened throughout TR, the provision in practice did not live up to the advertisements. This article discusses what went wrong, and particularly what might be done instead to meet this need under the new arrangements for probation services. To throw some light on what might be possible, it reviews some past 
research and past practice in resettlement services for this group, which was not in fact consistently neglected in the past.

First, what went wrong? Leaving aside for the moment the question of proportionality in a system which could face a prisoner with a whole year of supervision after a few days' imprisonment, the scheme was bedevilled with operational problems which are laid out in two devastating independent reports (HM Inspectorate of Probation: HMIP 2016, 2019b). Its consequences included high caseloads, and little actual help for most of those subject to it; for many it simply increased the risk of recall to prison for failure to comply with supervision requirements, even if no further offences were committed. The contracts between the Ministry of Justice and the CRCs required resettlement plans to be prepared for prisoners approaching release, but there was little evidence that these plans were implemented, and there was little contact between CRC 'through-the-gate' provision and resettlement teams in the prisons (HMIP 2016); some supervision was carried out with minimal contact (for example six-weekly telephone conversations: HMIP 2019b), the voluntary sector was used much less than was expected and promised by CRCs (HMIP 2018), prisoners and supervisors were confused by the system (Cracknell 2019), and the level of recalls to prison sharply increased. For example, of 38,617 people released under supervision from October 2017 to September 2018 8,994 were recalled to prison for failure to comply (HMIP 2019b). In the Justice Committee's 'Transforming Rehabilitation: Follow-Up’ report of July 2019 figures provided by the National Audit Office show that the number of prisoners recalled for breaching licence conditions increased by 47\% from January 2015 to September 2018 and that the proportion of recalled prisoners who were there following short sentences increased from $3 \%$ to $36 \%$. In other words, almost the whole increase was attributable to the new supervision arrangements for short-sentence prisoners (House of Commons Justice 
Committee 2019a). The Committee also commented that this disproportionately affects women as they are more likely to receive short prison sentences. Overall, the post-release supervision of short-term offenders stands out as one of the least successful parts of TR, but the shape and nature of future provision remains unclear, and many needs remain unmet among a short-sentence prison population which typically reconvicts at over $60 \%$ within a year of release. (The January to March 2017 cohort had a 64\% reconviction rate, as reported in HMIP 2019b). These problems are not unique to England and Wales: comparative studies in Europe, of which the most recent is an edited compilation covering 20 countries (Dünkel et al. 2018), show how many countries struggle to manage any continuity of services 'through the gate' or to overcome the structural disadvantages of the social environments from which many prisoners come. In Scotland, in spite of an approach to rehabilitation which draws explicitly on social work traditions, there is no compulsory post-release supervision for shortsentence prisoners, and rates of recall among other groups have been rising (McIvor et al. 2018).

Attempts to address the needs of short-sentence prisoners are not new: in fact they are older than the Probation Service. Local 'Discharged Prisoners Aid Societies' (DPAS) operated on a voluntary and charitable basis from the early $19^{\text {th }}$ century, and in 1879 the Liverpool Prison Gate Mission was offering a free breakfast to released prisoners together with an opportunity to sign a pledge to abstain from alcohol (Jarvis 1972). Local DPA Societies were eventually brought together in a National Association (NADPAS) which was the leading provider of prison after-care until this work was taken over by the Probation Service in the mid-1960s following a report of the Advisory Council on the Treatment of Offenders (Home Office 1963). NADPAS in due course became the penal reform group NACRO, but service provision remained a Probation Service responsibility. 
Arrangements for after-care of short sentence prisoners were covered by a general provision for voluntary after-care. The Probation Officers' Manual of 1974 explained that 'All persons discharged from prison except those subject to compulsory supervision' (at that time, mainly parolees and young prisoners) 'have a right to receive after-care from the probation and aftercare service on a voluntary basis. This right carries no obligation on the part of the exprisoner. Whether he exercises the right is a matter entirely for him to decide. Voluntary after-care carries no sanctions as to recall.' (Jarvis 1974). This entitlement ended 12 months after release, but could be extended. The vocabulary is noteworthy, apart from the use of the male pronoun (women were also eligible): the word 'care' appears frequently and was part of the title of what was then the Probation and After-Care Service. The modern term 'resettlement' did not replace 'after-care' and the related term 'through-care' (which was used to emphasize the need to begin work with the prisoner before release if possible) until a Home Office report in 1998, during Jack Straw's tenure as Home Secretary. That report argued that a term like 'through-care' was not widely understood, and could be 'associated with tolerance of crime' and 'more associated with the caring services' (Home Office 1998: 8). Newspeak replaced Oldspeak: New Labour wanted to be seen as tough on crime, and the vocabulary was changed to reflect this. (For a more detailed discussion of the theory and politics of through-care and resettlement see Raynor 2007.)

\section{The rise and fall of voluntary after-care}

The reality of voluntary after-care varied: in some areas specialist after-care teams existed, while in others most officers would have a few voluntary after-care 'clients' (another Oldspeak term). Often these were people already known through earlier involvement with the 
Service, for example on past probation orders. In addition there would be 'casual callers' looking for short-term practical assistance, often dealt with by whoever's turn it was to be Duty Officer for the day. By 1971 there were 9,288 active voluntary after-care cases, representing $29 \%$ of all after-care and $7 \%$ of the total Service caseload (Maguire et al. 1997). Helping these people was seen as a form of social work, often challenging because of their many problems and their social marginalization. This largely came to an end in 1984, when the Governments 'Statement of National Objectives and Priorities' required probation services to focus on the provision of information for Courts and the supervision of statutory cases (both community sentences and post-custodial compulsory supervision). Lower priority was to be attached to 'social work for offenders released from custody'.

Two other features of early after-care practice offer an interesting contrast to the TR system. Young offenders sentenced to Detention Centres (usually a three month sentence) or a Borstal Institution (a flexible sentence which could last up to two years but was usually much shorter) were subject to compulsory post-release supervision: this lasted for one year after Detention Centre and two years after Borstal. In both cases, however, there was provision for review of the supervision requirement and its early discharge: for example, officers supervising Detention Centre after-care were required to review it after six months and encouraged to recommend discharge if supervision was seen as no longer necessary or useful. Partly this was because the licensee who had done well for six months was seen as over the worst and likely to complete the year successfully: re-offending, if it occurred, tended to come early. However, supervision could also be reviewed if it was thought to be serving no useful purpose: people who were reluctant to be supervised and made little use of supervision but were not offending could benefit from 'suspension' of the supervision requirement. These provisions, which were quite regularly used by probation officers, were based on two 
assumptions: that it was constructive to shorten periods of post-release supervision when possible, and that supervision should be terminated when it no longer served a purpose - both assumptions which were missing in the design of the TR system. In addition, 'Recall . . is of limited value and should be used sparingly' (Jarvis 1974: 177).

By the end of the 1990s, in a Probation Service increasingly focused on monitoring, risk management and statutory supervision, a Home Office funded study showed that voluntary after-care had almost disappeared (Maguire et al. 1997, 2000). Of the 54 areas which made up the Probation Service in England and Wales at that time, 45 responded to a survey about their involvement in voluntary after-care work; the majority had less than ten live postrelease cases, and the Home Office estimated that there were only 750 such cases in the whole of England and Wales. Part of this decline was a consequence of the extension of statutory after-care to all prisoners sentenced to 12 months or more, who had been made subject to Automatic Conditional Release (Maguire, Perroud and Raynor 1996) accompanied by compulsory supervision, so that only prisoners serving shorter sentences were likely to fall within the scope of voluntary supervision. However, in many areas the decline clearly reflected policy: some service managers stated that voluntary cases were 'kept to an absolute minimum' or that 'the general rule is that VAC files should not be opened'. Only about one fifth of responding probation areas were actively promoting voluntary supervision to all short-sentence prisoners from their area; others promoted it with varying levels of selectivity and enthusiasm, and about a third actively discouraged officers from taking on voluntary cases. 
In addition to the post-release work which could be properly classified as after-care, there was some contact by home probation officers with serving prisoners, and it was clear that pre-release contacts, particularly visits, were associated with a much higher probability that contact would be maintained on release: of 11 surveyed case files which showed that an appointment for post-release contact had been made before release, eight showed that the appointment was kept. This was an early example of how continuity of contact 'through the gate' can be facilitated by pre-release contact with the people and services that will figure in post-release work. The problems which led to help being sought or offered included accommodation, money, family issues, substance abuse and self-management - in other words, much the same list of short-sentence prisoners' problems which reappears in most research on this group of prisoners. One of the policy options discussed by the researchers was the extension of statutory supervision to short-sentence prisoners, but this was seen as too costly and not pursued. (Interestingly, when this was eventually tried nearly twenty years later as part of TR little additional funding was made available, and this was widely seen as one reason for the poor results.)

\section{The Pathfinder experiments}

Recognition that this group of prisoners was receiving very little help led to further research. A renewed commitment to evidence-based practice and 'what works' in the late 1990s included several 'Pathfinder' research projects, and one was focused on how to improve 'resettlement' services (note the new terminology) for short-sentence prisoners. Over a thousand prisoners were involved in seven projects evaluated from 1999 to 2003, and the projects aimed to make additional help and support available both before and after release to increase the take-up of voluntary supervision. Four projects were led by probation services 
and three by voluntary organisations. The main findings can be found in two substantial reports (Lewis et al. 2003; Clancy et al. 2006) which contain a wealth of material, and some findings are particularly relevant to the question of how effective help might be made available to this group of prisoners. For example, early contact, well before the end of sentence, with relevant resources and helpful people, led to a proportion of prisoners opting in to voluntary through-care schemes which was considerably larger than the proportion found in the previous study, and an average of $37 \%$ of those initially signed up to projects were still in contact after release.

Probation-led projects aimed to have some impact on attitudes, thinking and offending behaviour as well as immediate welfare needs, while voluntary sector projects concentrated mainly on practical needs as defined by the prisoners. Many of the prisoners in the probationled projects had access to a short cognitive motivational programme, FOR (Focus On Resettlement: Fabiano and Porporino 2002), which aimed to strengthen their motivation to cope with problems outside prison and, most importantly, to introduce them to relevant resources: one of the programme sessions took the form of a 'market-place' in which representatives of statutory and voluntary services advertised what they could offer and had staff available to meet and discuss with prisoners. Results showed that the probation-led projects were associated with significantly more attitude change and continuity of service. This pattern was largely maintained in a reconviction follow-up: although the overall difference in performance between probation-led and voluntary-organisation-led projects did not reach statistical significance, the two projects with the best results were probation-led. Lower-than-expected reconviction rates were associated with post-release contact. Some voluntary-led projects used volunteer mentors for post-release contact with a small number of ex-prisoners, and this group had particularly low reconvictions within what were otherwise 
rather less effective projects. This may reflect the fact that mentors had more time to spend with people, and perhaps also that the help they offered was less associated with criminal justice officialdom. Those who attended the FOR programme showed lower-than-expected reconvictions if (and only if) they maintained post-release contact, which the programme aimed to encourage.

Some of these results appeared to fit well with some of the early desistance studies which had begun to emerge by this time. The importance of attitudes and motivation was underlined by Maruna's research on the narratives used by desisters and recidivists to explain and understand their lives (Maruna 2001). Briefly, recidivist narratives tended to describe being a victim of circumstances outside the offender's own control, so that reoffending is hard to avoid, whilst desisters tended to emphasize autonomy and self-determination, seeing themselves as having control over their own lives. A key element of desistance narratives was a belief that the offender had begun to take control of his or her own life: 'Whereas active offenders... seemed to have little vision of what the future might hold, desisting interviewees had a plan and were optimistic that they could make it work' (Maruna 2000, p.147). These ideas are also reminiscent of much earlier writing about resettlement: for example, 'The central object of after-care is to provide such guidance and moral support as will help the exprisoner to cope with his personal and peculiar difficulties, and to withstand the spirit of apathy and defeatism in which many are liable to drift back to crime' (Home Office 1953, p.16).

Another study by Zamble and Quinsey (1997) in Canada identified a pattern or process in which released prisoners typically faced problems after release, but either overcame them 
(drawing on optimism, resilience and confidence in their own capabilities) or reacted emotionally with pessimism and a belief that they would never succeed, that the odds were stacked against them and they might as well give up on the attempt to get by without offending. A more recent account of a rather similar process is provided by Halsey, Armstrong and Wright in their discussion of 'fuck-it moments' (Halsey et al. 2017) which happen when people try to do the right thing and to access help they know they need, but find that no actual help is provided, so why bother? Re-offending, they suggest, can be triggered by asking for help which you think has been promised but is not actually available. This underlines the risk of providing under-resourced services which promise much and deliver little. Many short-sentence prisoners have substantial criminal records, and services which aim to help them to desist should focus both on practical help and on changes in thinking.

Another discussion of the Pathfinder study (Raynor 2004) has explored the differences between these resettlement projects in terms of underlying assumptions about offending and desistance which constitute the 'implicit criminologies' of resettlement work. In that chapter a distinction is drawn between 'opportunity deficit' models, which regard offenders as victims of circumstances who offend because of lack of access to resources, and 'offender responsibility' models (perhaps better described as 'self-determination' models) which highlight the role of former prisoners' own decisions about how to respond to the circumstances in which they find themselves. Approaches based on 'opportunity deficit' tend to concentrate on welfare needs and on facilitating access to services, on the assumption that this will lead to desistance; approaches which emphasise ex-prisoners' own choices and their response to circumstances will also pay attention to thinking and motivation. This does not mean that people are somehow held responsible for circumstances and deficits which are completely beyond their control: this would be an example of the 'responsibilization' 
described by Rose [2000] and other critics of neoliberalism. The belief that the poor must be 'responsibilized', or treated as responsible for their own difficulties and for finding solutions to them, is one of the ideological underpinnings of neoliberalism: the wealthy can believe without dissonance that they deserve their wealth if they also believe that the poor deserve their poverty (Galbraith 1992). This results in blaming the poor for circumstances over which they have no control. However, the fact that some desirable changes are beyond the reach of individual ex-prisoners and their resettlement services does not mean that fatalism and passivity are the only appropriate responses. Services can focus on what is achievable, and on motivating people to achieve it. Individuals usually have some relative autonomy even in adverse circumstances, and can exercise some agency and choice. Resettlement services can be realistic about what can be achieved and can avoid reinforcing recidivist narratives. Former prisoners will often need help in developing the motivation and resourcefulness which will give them a better chance to manage their lives without offending. In the resettlement pathfinders, the projects led by voluntary organisations appeared more likely to operate on 'opportunity deficit' assumptions, and the greater success of some of the probation-led projects appeared to be due, in part, to their greater focus on thinking and motivation.

\section{Lessons for today}

These studies, based on voluntary take-up of resettlement supervision, have a number of implications for today's attempts to re-think short sentence resettlement. First, they encourage us to think about the process of opting-in to supervision. In reality even compulsory supervision requires cooperation from the supervisee, and supervision which is intended to address problems works best if there is a degree of agreement about what the 
problems are, and a degree of formal or informal consent to supervision. Supervision is only useful when it has a purpose; otherwise it is simply adding to the load of mass supervision and 'pervasive punishment' (McNeill 2019) which is proliferating in the world's penal systems. Supervision which provides neither control nor help but simply increases the risk of recall is not constructive, and can be harmful. In the short-sentence population some will require compulsory supervision on public protections grounds, and could usefully be under close supervision through such practices as Integrated Offender Management (Worrall and Mawby 2020); most, however, do not present this level of threat or danger, and it would be sensible to give them a degree of choice about whether or how to engage in resettlement supervision. The Pathfinders showed that realistic and positive engagement before release can lead to useful levels of opt-in from prisoners who might otherwise not know about services or not see the point of engaging. There is now an opportunity to think again about the level of coercion involved in resettlement supervision, and whether more use could be made of voluntary arrangements, as in the past. Some ex-prisoners will, of course, not want to take advantage of available services: the proportion is hard to predict, but if the offer is persuasive and personal and informed by the actual needs of the prisoner, take-up will be higher.

The Justice Committee's follow-up report (Justice Committee 2019a: 12) quotes evidence from HMIP that around a quarter of inspected short-sentence resettlement cases they saw were 'lower-risk so supervision periods could have potentially been shortened or suspended . .. we need to ... direct resources to where they are most needed'. In addition, as Maurice Vanstone points out (Vanstone 2016: 141) 'The strong message ... of cumulative research is that the creation of positive opportunities of change for people without a concomitant and genuine desire for change is likely to lead to failure.' A final point is that the first few weeks or months after release are the most difficult and risky time for many ex-prisoners, and 
voluntary projects show a concentration of contact in the early post-release period. This is another reason for questioning whether a year of post-release supervision, which appears so disproportionate in many cases, is really necessary. The old Detention Centre Licences were often discharged after six months because failure tended to come early, and if the ex-detainee was doing well at six months many practitioners thought that further supervision was unnecessary.

\section{The official responses so far}

It is interesting to compare these suggestions with some of the recent official attempts to address the same question. There is general consensus that a different approach is needed. The House of Commons Justice Committee reproduced three options drawn from evidence provided by Glenys Stacey, the Chief Inspector of Probation at that time and a consistent critic of TR (Justice Committee 2018: 52). The options are: a 'mirrored approach', matching the period of supervision to the sentence, so that, for example, a three month sentence would be followed by three months of supervision; a 'split approach', in which prisoners released, as is normal, at the half-way point of their sentence would be under supervision for the remainder of it (presumably, in the case of the three-month sentence, this would mean six weeks of supervision); and an 'assessment based' approach, with a maximum period of twelve months: 'the length of time under supervision would be determined by assessment and be needs led, with a focus on supporting resettlement and rehabilitation'. These are all interesting and share a concern that an automatic 12-month supervision period is disproportionate, not sufficiently flexible and not always necessary. The 'assessment-led' or needs-led approach is close to some of the suggestions arising from the research reviewed in this article, and could in principle operate on the basis that supervision which is neither 
requested nor useful should not be provided. Good practice in assessment includes participation by the assessed person, which could include the principle of consent in those cases where supervision is not a public protection issue.

The former Chief Inspector was right to raise the issue of proportionality in commenting on a system which subjected offenders with very different offences and sentences to the same 'one size fits all' supervision requirement. However, the alternative approach outlined here raises a different problem of proportionality. If post sentence supervision for some prisoners would be largely a consequence of opting in and of the prisoner's own choice, can it be proportional if they are subject to requirements, and the risk of recall, when others who received similar sentences for similar offences might choose not to be subject to similar requirements and risks? A full discussion of proportionality in resettlement is beyond the scope of this article, but a starting point might be to recognize that what I am suggesting is essentially a two-tier system. Prisoners whose offences indicate a real risk of harm requiring public protection would be subject to compulsory supervision, which would be part of the sentence and subject to the usual considerations of proportionality in sentencing. Others would be choosing to work with resettlement agencies to address problems, and it makes little sense for such people to be subject to recall if supervision does not succeed as intended. If nobody is subject to recall for failing to co-operate with a voluntary arrangement which they no longer want, their decision may sometimes be unwise but it would seem unfair and disproportionate to punish them for it. The comments about the limited value of recall which were made in the Probation Officer's Manual nearly half a century ago, and quoted near the beginning of this article, are still relevant. 
However, it is not clear that the former Chief Inspecctor's suggestions were designed to accommodate a voluntary principle to this extent. The Committee's preferred way forward was to recommend that Section 2 of the Offender Rehabilitation Act 2014, which started the 12-month compulsory supervision system, should be repealed within twelve months, by which time the Ministry of Justice was expected to develop proposals about what should replace it.

The Government's response to these recommendations (Justice Committee 2019a) was at first sight disappointing, as the recommendation to repeal was rejected. However, the response does indicate that the Government accepts that aspects of the current system are unsatisfactory, and this needs to be understood alongside other changes which are to be implemented in the resettlement of prisoners. The 'Draft Operating Blueprint' issued by HM Prison and Probation Service (HMPPS) in June of 2019 outlines a 'New Resettlement Model' (HMPPS 2019) which, among other changes, reintegrates the work of Through the Gate services (TTG) and resettlement teams in prisons, which had been found by inspectors to duplicate work and often to communicate poorly. Alongside this are changes in offender management which remove the unrealistic assumption that offender management can be carried out by the home probation officer throughout a long sentence, and instead specify that there will be a Responsible Officer undertaking offender management in the prison during the sentence, handing over to a community probation officer near the end. These are important changes to the 'NOMS Offender Management Model' (National Offender Management Service 2006) which was developed after the Carter Report of 2003, and the opportunities and risks presented by what is known as OMIC (Offender Management in Custody) have been discussed in more detail elsewhere (Maguire and Raynor 2017, 2020). These changes should, if adequately funded, produce a more integrated and effective system. For shorter 
sentences, the Responsible Officer will remain the home probation officer, and the Government's response to the Justice Committee includes the announcement that 'Where cases have no rehabilitative needs, and are assessed as low risk, a process will be put in place whereby the Responsible Officer may refer to their line manager for agreement of suspension of the Responsible Officer's face-to-face contact (with oversight undertaken by telephone contact)' (Justice Committee 2019b: 2). This is close to the provisions for suspension or early termination of supervision which were in regular use 50 years ago, and the new version of this could be a significant step in the right direction.

\section{Resources for resettlement}

One further problem concerns the resources available to make the system work. If supervision is under-resourced, carried out by overloaded or insufficiently trained staff or with a minimum of personal contact, it is not likely to provide significant help or to motivate supervisees to make an effort to cooperate or comply. At worst it becomes a way of pretending to help, inviting the 'fuck-it' response reported by Halsey et al. (2017). One important study of 'Through the Gate' provision suggested that 'instead of enhancing resettlement, Through the Gate is actually enhancing resentment ... deepening the sense of a penal crisis' (Taylor et al. 2017).If the human content of supervision is depleted, what is left can be simply a system of rules waiting to send you back to prison if you break them. The new Chief Inspector of Probation told the Justice Committee (2019a: 2) that 'As everyone knows, [TR] has brought 40,000 more people into the case load, people on short prison sentences who require follow-up support, but without additional money to deliver that'. Presumably the extra resource was to be delivered by magic, through the special powers of the private sector in which Ministers so obviously believed at the outset of TR. However, 
only an extreme optimist would believe that large amounts of new funding are now available to rescue the system. Two major sources of uncertainly make planning difficult: first, Government policy has been to bring about a reduction in the use of short sentences, which will in turn reduce the need for short-sentence resettlement supervision, but nobody knows when or how this will start to take effect, if at all. Secondly, the winning party in the General Election of December 2019 promised more money for the criminal justice system but appeared to be intending to spend this on more police, more prison places and longer sentences for some categories of offenders. In the few weeks that have elapsed between the election and the writing of this article it has not been possible to form any idea of how this will look in practice; however, there are many areas of underfunding in criminal justice after nine years of austerity policies. Legal aid and the Court system, to name just two, will be staking their own claims. We can hardly expect resettlement supervision to be at the top of the list. Any improvements in funding are more likely to be modest, and we need to consider how resources might be used more effectively.

One option is to target resources in an informed way where supervision is likely to be useful. When public protection is not the main concern, a consensus is emerging that supervision is not useful unless it meets needs and is helpful. Supervision which is not needed, requested or welcomed is usually a waste of resources and potentially counter-productive. Useful supervision would have a good prospect of voluntary take-up: some of the Pathfinder projects achieved voluntary opt-in to resettlement schemes of over $50 \%$ of eligible prisoners. Supervision is usually most important in the first few months after release, suggesting a standard period of six months rather than a year, and maybe three months after the shortest sentences. A very rough estimate is that taken together, a shorter supervision period, better targeting and less compulsion for lower-risk ex-prisoners could reduce the caseload from 
40,000 to around 15,000 , and further reduction might result from the proposed decrease in the use of short prison sentences. Funding a more adequate service for this number would be much more feasible than trying to continue with 40,000 additional underfunded cases, and the improved needs-led and evidence-based service which could result is surely a goal worth pursuing.

\section{Acknowledgment}

The author is grateful to the European Society of Criminology Working Group on Community Sanctions for comments and feedback on an earlier presentation of the ideas in this article.

\section{Declaration of Conflicting Interests}

The author declared no potential conflicts of interest with respect to the research, authorship and/or publication of this article.

\section{Funding}

The author received no financial support for the research, authorship and/or publication of this article, except as indicated in the text in respect of Home Office funding of related research. 


\section{References}

Carter P (2003) Managing Offenders, Reducing Crime: A New Approach. (Correctional Services Review.) London: Home Office.

Clancy, A., Hudson, K., Maguire, M., Peake, R., Raynor, P., Vanstone, M. and Kynch J. (2006)

Getting Out and Staying Out: results of the prisoner resettlement Pathfinders. Bristol: Policy Press.

Cracknell, M. (2019) 'Post Sentence Supervision: reform or replace?’ Paper to European Society of Criminology conference, Ghent, 19 September.

Dünkel, F., Pruin, I., Storgaard, A. and Weber, J. (2018) eds. Prisoner Resettlement in Europe. Abingdon: Routledge.

Fabiano, E. and Porporino, F. (2002) Focus on Resettlement - A Change. Canada: T3 Associates.

Galbraith, J. K. (1992) The Culture of Contentment. London: Sinclair-Stevenson.

Halsey M., Armstrong, R. and Wright, S. (2017) ' $\mathrm{F}^{* *} \mathrm{k}$ it! Matza and the mood of fatalism in the desistance process', British Journal of Criminology 57 (5) 1041-1060. 
HM Inspectorate of Probation (2016) An Inspection of Through-the-Gate Resettlement Services for Short-Term Prisoners. Manchester: HMIP.

HM Inspectorate of Probation (2018) Probation Supply Chains. Manchester: HMIP.

HM Inspectorate of Probation (2019a) Report of the Chief Inspector of Probation. Manchester: HMIP.

HM Inspectorate of Probation (2019b) Post-release supervision for short-term prisoners. Manchester: HMIP.

HM Prison and Probation Service (2019) The Proposed Future Model for Probation: a draft operating blueprint. London: HMPPS.

Home Office (1953) Report of the Committee on Discharged Prisoners'Aid Societies. Cmd. 8879. London: HMSO.

Home Office (1963) The Organisation of After-Care. Report of the Advisory Council on the Treatment of Offenders. London: HMSO.

Home Office (1984) Probation Service in England and Wales. Statement of National Objectives and Priorities. London: Home Office. 
Home Office (1998) Joining Forces to Protect the Public: Prisons-Probation. London: Home Office.

House of Commons Justice Committee (2018) Transforming Rehabilitation. HC482. London: House of Commons.

House of Commons Justice Committee (2019a) Transforming Rehabilitation: Follow-up. HC2526. London: House of Commons.

House of Commons Justice Committee (2019b) Transforming Rehabilitation: Follow-up: Government Response to the Committee's Nineteenth Report of Session 2017-2019. www.parliament.uk accessed 30 October 2019.

Jarvis, F. (1972) Advise, Assist and Befriend: the History of the Probation Service. London: National Association of Probation Officers.

Jarvis, F. (1974) Probation Officers' Manual. Second edition. London: Butterworths.

Lewis, S., Vennard, J., Maguire, M., Raynor, P., Vanstone, M., Raybould, S. and Rix, A. (2003) The resettlement of short-term prisoners: an evaluation of seven Pathfinders, RDS Occasional Paper 83. London: Home Office. 
Maguire, M., Perroud, B. and Raynor, P. (1996) Automatic Conditional Release: the first two years, Research Study 156, London: Home Office.

Maguire, M. and Raynor, P. (2017) 'Offender management in and after prison: the end of "end to end"' Criminology and Criminal Justice 17 (2) 138-157.

Maguire, M. and Raynor, P. (2020) 'Preparing prisoners for release: current and recurrent challenges' in Ugwudike, P., Graham, H., McNeill, F., Raynor, P., Taxman, F. S. and Trotter, C. (eds) The Routledge Companion to Rehabilitative Work in Criminal Justice. Abingdon: Routledge, chapter 42, pp. 520-532.

Maguire, M., Raynor, P., Vanstone, M. and Kynch, J. (1997) Voluntary After-Care: report to the Home Office. Cardiff: Michael and Associates.

Maguire, M., Raynor, P., Vanstone, M. and Kynch, J. (2000) 'Voluntary After-Care and the Probation Service: a case of diminishing responsibility', Howard Journal of Criminal Justice 39(3): 234-248.

Maruna, S. (2001) Making Good. Washington: American Psychological Association. 
McIvor, G., Graham, H. and McNeill, F. (2018) 'Prisoner Resettlement in Scotland', in Dünkel, F., Pruin, I., Storgaard, A. and Weber, J. eds. Prisoner Resettlement in Europe. Abingdon: Routledge.

McNeill, F. (2019) Pervasive Punishment. Bingley: Emerald.

Raynor, P. (2004) 'Opportunity, Motivation and Change: Some Findings from Research on Resettlement' in Burnett, R. and Roberts, C. (eds), What Works in Probation and Youth Justice. Cullompton, Devon: Willan, 217-33.

Raynor, P. (2007) 'Theoretical perspectives on resettlement: what it is and how it might work', in Hucklesby, A. and Hagley-Dickinson, L. eds. Prisoner Resettlement Policy and Practice, Cullompton: Willan, pp. 26-42.

Rose, N. (2000) 'Government and Control', British Journal of Criminology 40 (2) 321-339.

Vanstone, M. (2016) 'What is probation's role in successful social integration (resettlement) of people leaving prison? A piece in the jigsaw' in McNeill, F., Durnescu, I. and Butter, R. eds. Probation 12 Essential Questions. London: Palgrave, pp. 129-151.

Worrall, A. and Mawby, R. (2020) 'Integrated Offender Management and rehabilitation for adult offenders in England and Wales' in Ugwudike, P., Graham, H., McNeill, F., Raynor, P., Taxman, F. S. and Trotter, C. (eds) The Routledge Companion to Rehabilitative Work in Criminal Justice. Abingdon: Routledge, chapter 74, pp. 902-912. 
Taylor, S., Burke, L., Millings, M. and Ragonese, E. (2017) 'Transforming Rehabilitation during a penal crisis: a case study of Through the Gate services in a resettlement prison', European Journal of Probation 9 (2) 115-131.

Zamble, E. and Quinsey, V. (1997) The Criminal Recidivism Process. Cambridge:

Cambridge University Press. 